\title{
Tratamento de feridas: análise da produção científica publicada na Revista Brasileira de Enfermagem de 1970-2003
}

Wound treatment: scientific production analysis published in the Revista Brasileira de Enfermagem from 1970-2003

Tratamiento de heridas: análisis de la producción científica publicada en la Revista Brasileira de Enfermagem de 1970-2003

\section{Ângela Lima Pereira}

Enfermeira. Aluna do Programa de PósGraduação Mestrado em Enfermagem, da Faculdade de Enfermagem da Universidade Federal de Goiás. ginha.ange@bol.com.br

Maria Márcia Bachion

Enfermeira. Doutora em Enfermagem, Professora Titular da Faculdade de Enfermagem da Universidade Federal de Goiás. mbachion@fen.ufg.br

\section{RESUMO}

Esta revisão bibliográfica sistematizada teve como objetivo analisar a produção científica acerca da utilização de produtos no tratamento de feridas, publicada na REBEn de 1970 a 2003. Consultamos todos os números da revista publicados no período, identificando 41 artigos de interesse. Após leitura dos mesmos, incluímos na amostra 11 textos. Identificamos maior publicação na década de 1990, predominando autores da área assistencial, delineamento quase-experimental e de relato de experiência. Os produtos estudados foram papaína, própolis, açúcar, bota de Unna, carvão ativado, filme transparente, membrana amniótica, clara de ovo, colagenase, hidrocolóide, alginato de cálcio, pomadas antimicrobianas, ácidos graxos essenciais, fibras de viscose e poliéster. Os resultados encontrados denotam efeitos positivos da utilização dos produtos.

Descritores: Bandagens; Curativos oclusivos; Cuidados de enfermagem.

\section{ABSTRACT}

This systematic review aimed to analyze the scientific production concerning the use of products in the treatment of wounds, published by REBEn from 1970 to 2003. We consulted all numbers of the journal published in the period, identifying 41 articles of interest. After an appraisal reading we included 11 papers in the sample. We identified a larger publication in the decade of 1990, prevailing authors of the attendance area, almost-experimental plan and experience repor. The studied products were papain, propolis, sugar, Unna boot, activated coal, transparent film, amniotic membrane, albumin, collagenase, hydrocolloid dressing, calcium alginate, anti-bacterial agents, essential greasing acids, viscose fibers and polyester. The findings demonstrated they denote positive effects of the use of the products.

Descriptors: Bandages; Occlusive dressings; Nursing care.

\section{RESUMEN}

Esta revisión bibliográfica sistematizada tuvo como objetivo analizar la producción científica respecto a la utilización de productos en el tratamiento de heridas, publicada en la REBEn de 1970 a 2003. Consultamos todos los números de la revista publicados en el periodo, identificando 41 artículos de interés. Después de la lectura de los mismos, incluimos en la nuestra 11 textos. Identificamos mayor publicación en la década del 1990, predominando autores del área asistencial, delineamiento casi-experimental y de relato de experiencia. Los productos estudiados fueron papaína, propolis, azúcar, bota de Unna, carbón activado, película transparente, membrana amniótica, albumina, colagenasa, hidrocolóide, alginato de calcio, ungüentos antimicrobianas, ácidos grasos esenciales, fibras de viscosa y poliéster. Los resultados encontrados denotan efectos positivos de la utilización de los productos.

Descriptores: Vendajes; Apositos oclusivos; Atención de enfermería.

Pereira AL, Bachion MM. Tratamento de feridas: análise da produção científica publicada na Revista Brasileira de Enfermagem de 1970-2003. Rev Bras Enferm 2005 mar-abr; 58(2):208-13.

\section{INTRODUÇÃO}

Ferida pode ser definida como qualquer alteração da integridade anatômica da pele, resultante de qualquer tipo de trauma ${ }^{(1)}$.

O tratamento de feridas envolve aspectos sistêmicos e locais, que são desenvolvidos por profissionais de diferentes áreas.

O tratamento local é denominado curativo, que constitui do procedimento de limpeza e cobertura de uma lesão, com o objetivo de auxiliar o restabelecimento da integridade do tecido ou prevenir a colonização dos locais de inserção de dispositivos invasivos diagnósticos ou terapêuticos (por exemplo, cateteres, drenos) $)^{(1)}$.

A preocupação com o tratamento de feridas é antiga e muitos estudos acerca do assunto têm 
sido desenvolvidos ${ }^{(2-6)}$, o que levou a um grande avanço no conhecimento dos diferentes tipos de lesões, do processo de reparação do tecido lesado, bem como de todos os fatores nele envolvidos. Também propiciou o desenvolvimento de um arsenal de produtos a serem utilizados no tratamento de feridas.

Esse avanço do conhecimento no tratamento de feridas, também contribuiu para que profissionais de saúde envolvidos neste cuidado pudessem revisar conceitos e práticas, e reconhecer que a lesão é apenas mais um aspecto dentro de um todo, que é o ser humano(6). Dessa forma, é fundamental que cada portador de feridas seja visto como um ser único e, cada caso exige avaliação específica.

No atendimento à pessoa portadora de ferida, o enfermeiro deve avaliar o estado geral de saúde do cliente e em especial as condições da lesão. Disto depende a escolha do material adequado a ser utilizado, no sentido de ajudar o organismo a realizar o trabalho, que é fundamentalmente endógeno ${ }^{(7)}$.

Existem mais de 2.000 produtos para tratar feridas no mercado, 0 que torna a escolha do curativo correto uma tarefa difícil e desafiadora. Nesse sentido alguns fatores devem ser considerados ${ }^{(5)}$.

- Fatores relacionados com a ferida e a pele adjacente - etiologia, tamanho, profundidade, localização anatômica, volume de exsudato, risco ou presença de infecção, condições da pele adjacente.

- Fatores relacionados com o paciente - condições nutricionais, doenças de base, necessidade de controle da dor, preferências.

- Fatores relacionados com o curativo - indicação, contra-indicação, vantagens e desvantagens, disponibilidade, durabilidade, adaptabilidade, e facilidade de uso.

Nos últimos anos, a enfermagem tem aumentando o interesse em buscar evidências científicas para resolver problemas complexos da prática assistencial( ${ }^{(8)}$, assim como outras áreas da saúde ${ }^{(9)}$. Muitos produtos têm sido utilizados no tratamento de feridas, sem que a enfermagem conheça com exatidão os mecanismos de ação e resultados do contato destas substâncias como as lesões. Rever a produção científica dos enfermeiros sobre a temática pode contribuir para evidenciar o estado d'arte da apropriação, utilização e desenvolvimento de tecnologias de cuidado na área de tratamento de feridas na nossa profissão.

O periódico de enfermagem mais antigo no Brasil é a Revista Brasileira de Enfermagem (REBEn), a qual é editada pela Associação Brasileira de Enfermagem (ABEn) desde 1932. Acreditamos que a mesma tem prestado relevante contribuição na divulgação do conhecimento da Enfermagem em várias áreas, contudo ainda não fo analisada sua contribuição relativa a temática que ora focalizamos.

\section{OBJETIVO}

Esta pesquisa teve como objetivo analisar a produção científica publicada na Revista Brasileira de Enfermagem acerca do tratamento de feridas, no período de 1970 a 2003.

\section{MÉTODO}

Tratou-se de uma pesquisa de revisão sistemática da literatura. Esse tipo de estudo representa uma mudança na revisão bibliográfica tradicional e tem como principal alcance integrar a informação existente sobre uma temática específica, através do agrupamento e análise de resultados procedentes de estudos primários, permitindo a geração de suporte científico para a seleção de condutas ${ }^{(10)}$.

\subsection{Amostra}

Foram incluídos artigos publicados na Revista Brasileira de Enfermagem que atenderam aos seguintes critérios de inclusão:

- ser publicado no período de 1970 a 2003.

- desenvolver aplicação de produtos no tratamento de feridas em

\section{seres humanos.}

\subsection{Coleta de dados}

Mediante consulta manual a cada número da Revista Brasileira de Enfermagem e leitura do sumário de artigos, selecionamos inicialmente 41 artigos que pelo título indicavam tratar do tema estudado. Os textos foram lidos na íntegra e analisados quanto ao preenchimento dos critérios de inclusão. Foram excluídos 28 artigos por tratar-se de revisão bibliográfica, nota prévia, proposta de sistematização de tratamentos, prevenção de feridas, reabilitação, cuidados com ostomias, cálculo de custo de curativos, ensino da técnica de curativos, fatores de risco para feridas, a vivência do portador de feridas, índice de contaminação de cateteres venosos. Assim, a amostra desta pesquisa constou de 11 artigos, que foram lidos, novamente, na íntegra para preenchimento do instrumento de coleta de dados. $\mathrm{O}$ instrumento de coleta de dados constou de uma ficha com dados de identificação dos artigos, descrição do número de autores, formação profissional e área de atuação dos mesmos, dados para análise do estudo, como título da obra, palavras chave, tipo de pesquisa, material, procedimento e método de análise, resultados encontrados, considerações finais.

\subsection{Análise de dados}

Foi realizada análise estatística descritiva utilizando-se freqüência simples para descrever os achados referentes aos seguintes dados: ano de publicação, área de atuação e titulação dos autores, tipo de estudo, tema principal. Foi elaborado um quadro sinóptico com os resultados obtidos nas pesquisas analisadas, com colunas para identificação, procedimentos e resultados encontrados.

\section{RESULTADOS}

Dos 11 artigos que trataram da aplicação de produtos no tratamento de feridas, um foi publicado na década de 70 , três foram publicados na década de 80, e sete foram publicados na década de 90 . Não encontramos nenhum artigo publicado após 1999, que seguisse os critérios de inclusão. Provavelmente, a maior concentração dos estudos na década de 90 tenha ocorrido devido à introdução crescente de novos produtos na prática do tratamento de feridas a partir deste período em nosso país.

A autoria dos artigos envolveu a participação de profissionais de diferentes áreas do conhecimento, incluindo vinte e um enfermeiros, um médico, um biomédico, um técnico de enfermagem. Seis não apresentavam especificação da formação profissional. Embora o cuidado com as feridas seja realizado principalmente por enfermeiros, não é exclusivo desta área profissional. 0 tratamento de feridas constitui em um campo e práxis que é multiprofissional, contudo, a atuação interdisciplinar ainda é incipiente, como mostra o perfil dos autores, quanto à atuação profissional. $O$ número de autores dos artigos variou de 1 a 4, sendo na maioria dos casos (5 artigos) quatro autores envolvidos. A necessidade de maior conhecimento na realização dos cuidados com as feridas, parece despertar profissionais da área da assistência para a pesquisa. Conforme pudemos verificar neste estudo, quanto à área de atuação dos 30 autores, 19 deles estavam ligados a serviços de saúde e 11 exerciam atividades ligadas ao ensino. Talvez, 0 estudo desta temática vá ao encontro à necessidade dos enfermeiros que atuam na assistência de avaliarem sua prática no cuidado de feridas.

Quanto ao tipo de estudo, houve maior freqüência de pesquisas do tipo quase-experimental (5 estudos). Considera-se pesquisa quaseexperimental aquelas em que "envolvem a manipulação de uma variável independente, isto é, a instituição de um tratamento", mas que "carecem da distribuição aleatória ou grupo de controle que caracteriza os experimentos reais"(11). A seguir, verificou-se a realização de estudos do tipo relato de experiência (4 estudos). Houve, ainda, presença de dois outros tipos de estudo: um experimental, considerando ser aquele em que "o investigador manipula a variável independente, administrando um tratamento experimental a alguns sujeitos, ao mesmo tempo em 
que não o faz a outros (ou administra tratamento alternativo)"; e uma pesquisa descritiva, compreendida como aquela na qual se observam os eventos, sem intervir sobre os mesmos ${ }^{(11)}$.

Embora o número de artigos tenha sido pequeno, é possível observar a tendência para a realização cada vez maior de estudos do tipo quaseexperimento. Dada a natureza do tema de investigação, é delicada a realização de experimentos controlados, pois deixar pessoas com feridas sem tratamento ou empregar substância placebo não mais se justifica, pois há excelentes produtos disponíveis no mercado e, do ponto de vista ético, a recomendação é que a comparação seja feita com o melhor produto disponível. Os profissionais ligados à assistência demonstraram preparo diferenciado para a pesquisa, uma vez que não é comum esta atividade nos serviços em geral.

Os temas abordados nas pesquisas publicadas na REBEn durante o período estudado conforme mostra o quadro 1 foram o uso de papaína tanto em feridas abertas no geral como em feridas infectadas (2 estudos), 0 uso de própolis em lesões abertas, infectadas (1 estudo), uso de açúcar em ferida infectada (1 estudo), utilização de bota de Unna e o carvão ativado em úlcera de estase venosa (1 estudo), aplicação de filme transparente em áreas doadoras para enxerto de pele e áreas com queimaduras de grau I e II (1 estudo), uso de membrana amniótica em queimaduras de I, II, III e IV graus (1 estudo), uso de clara de ovo em dermatite amoniacal (1 estudo), utilização de colagenase em úlceras de pressão (1 estudo), comparação do efeito de pomada antimicrobiana e quaternário de amônio em curativos de cateteres venosos centrais (1 estudo). Ainda, foi abordada em um artigo, a utilização de vários produtos (colagenase, pomadas antimicrobianas, sacarose, sulfadiazina de prata, ácidos graxos essenciais, fibras de viscose e poliéster, hidrocolóide e alginato de cálcio) em estudo comparativo do custo do tratamento de feridas.

\begin{tabular}{|c|c|c|}
\hline Identificação & Amostra, Procedimento e Método de Análise & Resultados \\
\hline Azevedo(12) & $\begin{array}{l}\text { Amostra: } 51 \text { pacientes com queimaduras de diversos graus. Procedimento: no pequeno queimado foi } \\
\text { realizada limpeza da área com SF; desbridamento somente das flictenas rotas; cobertura da área } \\
\text { cruenta com membrana amniótica; ainda, utilizou-se pomada do tipo gentamicina ou similar em áreas } \\
\text { infectadas, e fornecida orientação para curativos ambulatoriais. No grande queimado foi realizada } \\
\text { limpeza vigorosa com SF, tricotomia quando necessário; desbridamento somente das flictenas rotas; } \\
\text { quando possível, o paciente foi submetido a balneoterapia; após, foi colocado sobe campo estéril, com } \\
\text { técnica asséptica e aplicado a membrana amniótica na área cruenta, primeiro em locais de maior atrito } \\
\text { e mais dolorosos. A membrana ficou aderente à lesão, sem bolhas; observado a posição anatômica da } \\
\text { região afetada. O paciente foi protegido com arco próprio, e coberto com campo estéril. Análise: } \\
\text { mediante observação e registro no prontuário do paciente. }\end{array}$ & $\begin{array}{l}48 \text { pacientes obtiveram cura; } 2 \text { morreram (os mais } \\
\text { graves, com } 48 \% \text { de área corpórea comprometida); } \\
\text { um paciente foi transferido para outra cidade, após } \\
\text { cuidados iniciais. }\end{array}$ \\
\hline $\begin{array}{l}\text { Haddad, } \\
\text { Vannuchi, } \\
\text { Chenso, } \\
\text { Hauly(13) }\end{array}$ & $\begin{array}{l}\text { Amostra: } 100 \text { pacientes com feridas infectadas, independente da raça, sexo e idade. Procedimento: } \\
\text { limpeza da lesão com SF, cobertura da lesão com açúcar, até não mais visualizar o leito da ferida; } \\
\text { oclusão com gaze ou compressa, de acordo com a necessidade. Todo material estéril, exceto } 0 \\
\text { açúcar. Em locais de difícil aderência, utilizou-se pasta constituída de } 90 \% \text { de açúcar e } 10 \% \text { de } \\
\text { furacin. O curativo foi trocado a cada } 8 \text { horas até diminuir secreção e aparecer tecido de granulação, } \\
\text { depois a cada } 12 \text { horas e uma vez ao dia, até cicatrizar. Antibioticoterapia foi utilizada durante } 7 \text { a } 10 \\
\text { dias do pós-operatório. Este relato reflete a experiência dos autores com o uso do açúcar num período } \\
\text { de } 30 \text { meses. }\end{array}$ & $\begin{array}{l}\text { Em torno do } 5^{\circ} \text { e } 7^{0} \text { dia do tratamento, surgiu } \\
\text { gradativamente o tecido de granulação e } \\
\text { desapareceu a secreção purulenta assim como o } \\
\text { odor. O estado nutricional precário de alguns } \\
\text { pacientes retardou a cicatrização. Alguns doentes } \\
\text { não chegaram ao final do tratamento em decorrência } \\
\text { do grave estado geral e óbito antes da cicatrização. } \\
0 \text { odor nas gangrenas não desapareceu, porém } \\
\text { diminuiu com a redução da área. Os resultados } \\
\text { foram positivos em portadores de diabetes, sem } \\
\text { efeitos colaterais. }\end{array}$ \\
\hline $\begin{array}{l}\text { Robazzi, } \\
\text { Bechelli, } \\
\text { Levy, } \\
\text { Moriya(14) }\end{array}$ & $\begin{array}{l}\text { Amostra: } 35 \text { pacientes com idades entre } 7 \text { e } 75 \text { anos que necessitavam de cateterização intravenosa; } \\
\text { distribuídos em três grupos, o primeiro com } 11 \text {, o segundo com } 13 \text { e o terceiro com } 11 \text { pacientes. } \\
\text { Procedimento: No grupo A, foi realizado limpeza com éter ou benzina, anti-sepsia da pele com } \\
\text { quaternário de amônio e oclusão com gaze e esparadrapo; as trocas foram } 2 \text { vezes ao dia; no grupo } \\
\text { B, foi seguido o mesmo procedimento, e acrescido uso de pomada antimicrobiana em volta da } \\
\text { inserção do cateter, com trocas de curativos a cada } 2 \text { dias; no grupo C, assistência foi prestada pela } \\
\text { equipe da instituição, sem determinação de tempo e troca, e do produto utilizado. Feito coleta de } \\
\text { material para exame microbiológico da no local a ser puncionado e ponta do cateter antes da inserção } \\
\text { do mesmo, e após a punção a cada troca de curativo, e antes do uso do produto. Nos grupos A e B foi } \\
\text { realizado anti-sepsia do equipo quatro vezes ao dia, e troca dos equipos a cada } 2000 \mathrm{ml} \text { de solução } \\
\text { infundida. Análise: estatística descritiva simples. }\end{array}$ & $\begin{array}{l}\text { A média de permanência dos cateteres foi menor no } \\
\text { grupo A. Os resultados de cultura das extremidades } \\
\text { dos cateteres foram positivos em 20\%, todos } \\
\text { pertencentes aos grupos B e C. No grupo A, os } \\
\text { resultados de cultura das extremidades distais dos } \\
\text { cateteres e dos curativos foram negativas. A média } \\
\text { de intervalo das trocas dos curativos foi de dois dias } \\
\text { para os grupos A e B, e de } 5,07 \text { dias no grupo C. }\end{array}$ \\
\hline Monetta(15) & $\begin{array}{l}\text { Amostra: } 15 \text { pacientes com lesões abertas, num total de } 23 \text { lesões; } 1 \text { em tratamento ambulatorial, os } \\
\text { demais em tratamento hospitalar. Procedimento: solicitado autorização do paciente e equipe médica } \\
\text { responsável. Realizado orientação a equipe de enfermagem quanto ao tratamento. Técnica utilizada: } \\
\text { (1) Preparo da solução de papaína diluindo o pó da enzima em água destilada, na proporção de uma } \\
\text { colher de café rasa da enzima, para } 50 \text { cc de água destilada; limpeza mecânica da lesão com gaze } \\
\text { embebida na solução de papaína; cobertura da lesão com gaze embebida em solução de papaína, } \\
\text { preenchendo todos os contornos da lesão; em áreas de tecido necrosado, cobertura com fina camada } \\
\text { de papaína em pó; em áreas de camada de necrose espessa, fazendo riscos com bisturi, para } \\
\text { favorecer a absorção da enzima; cobertura secundária com gazes secas e fixação com fita adesiva. (2) } \\
\text { Utilizado mamão verde: o mamão foi lavado com água e sabão, e colocado em recipiente estéril; com } \\
\text { técnica asséptica, cortado e retiradas as sementes; raspado a poupa e guardada em recipiente } \\
\text { esterilizado; realizado limpeza da lesão com SF; aplicado o raspado na lesão, preenchendo toda área; } \\
\text { cobertura com gaze seca e fixação com fita adesiva. Somente no primeiro paciente foi utilizado } \\
\text { mamão. A cada curativo, realizado retirada do tecido necrosado amolecido, com auxílio de gaze } \\
\text { úmida. Análise: através de observação diária ou a cada } 5 \text { dias, quanto à cor da lesão e área ao redor, } \\
\text { presença ou não de tecido necrosado, comprometimento tecidual, presença de secreção e } \\
\text { característica da secreção; e mensuração (comprimento X largura X profundidade). }\end{array}$ & $\begin{array}{l}\text { No } 5^{\circ} \text { dia observou-se aumento da secreção de } \\
\text { aspecto sero-purulenta, amolecimento do tecido } \\
\text { necrosado, afrouxamento dos bordos com pequeno } \\
\text { aumento do tamanho da lesão; diminuição do alo de } \\
\text { hiperemia ao redor da lesão. No decorrer do } \\
\text { tratamento, após desbridamento da lesão pela } \\
\text { própria papaína, observou-se diminuição progressiva } \\
\text { da secreção e crescimento do tecido de granulação, } \\
\text { bem como aparecimento de tecido cicatricial que } \\
\text { aumentou de fora para dentro. Dos } 15 \text { pacientes } \\
\text { acompanhados, } 3 \text { foram submetidos a enxerto de } \\
\text { pele na fase de aparecimento do tecido de } \\
\text { granulação, sendo estes nos } 21^{\circ}, 29^{\circ} \text { e } 43^{\circ} \text { dia de } \\
\text { tratamento; } 2 \text { tiveram óbito, no } 8^{\circ} \text { e } 12^{\circ} \text { dia de } \\
\text { tratamento; } 1 \text { caso suspenso no } 13^{\circ} \text { dia devido } \\
\text { queixa de dor; e } 5 \text { pacientes receberam alta } \\
\text { hospitalar com lesões já em fase de cicatrização. } \\
\text { Dos } 15, \text { paciente, apenas } 5 \text { queixaram ardor } \\
\text { moderado que diminuiu gradativamente, durando no } \\
\text { máximo } 20 \text { minutos até cessar totalmente. Não } \\
\text { houve caso de alergia. }\end{array}$ \\
\hline
\end{tabular}

Quadro 1. Primeira parte da sinopse dos artigos analisados. REBEn 1970-1987. 


\begin{tabular}{|c|c|c|}
\hline Identificação & Amostra, Procedimento e Método de Análise & Resultados \\
\hline $\begin{array}{l}\text { Bernardo, } \\
\text { Souza, } \\
\text { Colavitti, } \\
\text { Garcia(16) }\end{array}$ & $\begin{array}{l}\text { Amostra: } 10 \text { paciente, sendo } 8 \text { mulheres e } 2 \text { homens, com idades entre } 22 \text { e } 57 \text { anos, apresentando } \\
\text { lesões abertas. Procedimento; preparo da solução (30g de própolis em } 100 \mathrm{ml} \text { de álcool etílico, ou } \\
\text { após teste de tolerância ao produto, aplicando } 1 \text { a } 2 \mathrm{ml} \text { do extrato diretamente sobre a lesão, rediluído } \\
\text { o extrato em } 30 \text { a } 50 \% \text { de água destilada); limpeza da lesão com SF e desbridamento; cobertura } \\
\text { primária da lesão com gaze embebida na solução de própolis; cobertura secundária com gazes secas } \\
\text { e enfaixamento com ataduras de crepe. O pacientes eram atendidos no ambulatório a cada } 7 \text { ou } 15 \\
\text { dias. Os pacientes foram orientados a fazer o curativo no domicílio após o banho, lavando a lesão com } \\
\text { água fervida e sabão de coco; cobrir a lesão com gaze ou pano limpo e seco e enfaixar com atadura e } \\
\text { trocar o curativo uma ou duas vezes ao dia. Análise: as lesões foram observadas quanto à presença } \\
\text { de secreção, aspecto, odor; extensão e comprometimento tecidual, aspecto do tecido são ao redor da } \\
\text { área comprometida. Mensuração (comprimento e largura) por meio de régua ou fita métrica, no início } \\
\text { do tratamento e a cada } 15 \text { dias. A avaliação foi subjetiva (informações prestadas pelo paciente) e } \\
\text { objetiva (negativação da cultura, diminuição das medidas e aspecto fotográfico). }\end{array}$ & $\begin{array}{l}\text { Na primeira semana de uso da própolis, notou-se } \\
\text { "limpeza" da ferida; após a primeira semana, } \\
\text { melhora do odor das secreções e na sensibilidade } \\
\text { dos pacientes devido a ação anestésica da própolis. } \\
\text { Cultura indicando diminuição de microrganismos, em } \\
\text { alguns casos após as } 48 \text { horas chegando a } \\
\text { inativação. Não foram observadas reações alérgicas. }\end{array}$ \\
\hline $\begin{array}{l}\text { Silva, } \\
\text { Menezes, } \\
\text { Souza, } \\
\text { Gimenez }\end{array}$ & $\begin{array}{l}\text { Amostra: } 55 \text { pacientes, de ambos os sexos; } 33 \text { com idades entre } 9 \text { meses e } 40 \text { anos, apresentando } \\
\text { queimaduras de } 2^{\circ} \text { grau, superficiais, e } 22 \text { idades entre } 9 \text { e } 70 \text { anos, com área doadora de enxerto de } \\
\text { pele. Procedimento: Realizada limpeza com SF e/ou água e sabão neutro, desbridamento. Na área } \\
\text { doadora de pele, para hemostasia foi aplicada compressa de SF gelado, ou solução de adrenalina, ou } \\
\text { enfaixamento com atadura de crepe. Em todos os casos foi realizado desengorduramento da pele com } \\
\text { benzina ou similar; em casos onde houve excesso de exsudato, aspiração por punção com agulha } \\
\text { hipodérmica estéril e aplicação de remendo de um novo filme no orifício da punção. Feito colheita do } \\
\text { material microbiológico do leito da ferida com cotonete no primeiro dia de internação para controle } \\
\text { microbiológico. Análise: os critérios de observação incluíram tempo de permanência e troca de filmes, } \\
\text { acúmulo de exsudato, fenômenos irritativos da pele adjacente, tempo de epitelização, ocorrência de } \\
\text { infecção. }\end{array}$ & $\begin{array}{l}\text { Pacientes com queimaduras: } 66,7 \% \text { apresentaram } \\
\text { epitelização; } 1,15 \% \text { abandonaram o tratamento, } \\
9,1 \% \text { foram excluídos da pesquisa por problemas } \\
\text { técnicos. No grupo de áreas doadoras de pele, todos } \\
\text { apresentaram completa epitelização. O tempo de } \\
\text { permanência dos filmes foi de } 1 \text { a } 14 \text { dias, sendo na } \\
\text { maioria de } 5 \text { a } 9 \text { dias. A freqüência de trocas variou } \\
\text { de nenhuma a 2, sendo na maioria das vezes } \\
\text { nenhuma ou apenas } 1 \text { troca. O tempo médio de } \\
\text { epitelização foi de } 5 \text { a } 14 \text { dias, sendo } \\
\text { predominantemente, de } 5 \text { a } 9 \text { dias para ambas as } \\
\text { lesões. } 45 \% \text { apresentaram epitelização sem que } \\
\text { houvesse necessidade de nenhuma troca do filme. } \\
\text { Entre os que apresentaram exsudato, sem haver } \\
\text { necessidade de troca dos filmes, o tempo de } \\
\text { absorção pelo organismo variou de } 1 \text { a } 10 \text { dias, } \\
\text { sendo na maioria } 1 \text { a } 2 \text { dias para queimaduras e } 3 \text { a } \\
5 \text { dias para áreas doadoras. Tempo e número de } \\
\text { trocas: (1) áreas de queimaduras: curativo } \\
\text { tradicional, } 1 \text { atendimento e } 2 \text { trocas em } 60 \text { minutos, } \\
\text { e curativo transparente, } 1 \text { atendimento e nenhuma } \\
\text { troca em } 20 \text { minutos.; (2) áreas doadoras de pele: } \\
\text { curativo tradicional, e atendimento e } 4 \text { trocas, em } 1 \\
\text { hora e } 15 \text { minutos, e curativo transparente } 1 \\
\text { atendimento sem trocas, em } 20 \text { minutos. } 0 \text { custo } \\
\text { individual dos curativos nos casos sem } \\
\text { intercorrência: no grupo de queimaduras, o curativo } \\
\text { transparente foi } 55 \% \text { mais barato do que } 0 \\
\text { tradicional; no grupo de doadores de pele, } 65 \% \text { mais } \\
\text { barato do que o tradicional. Não houve evidência } \\
\text { clínica de infecção em nenhum dos casos tratados. }\end{array}$ \\
\hline $\begin{array}{l}\text { Silva, } \\
\text { Confalonieri, } \\
\text { Amorin(18) }\end{array}$ & $\begin{array}{l}\text { Amostra: } 35 \text { crianças com dermatite amoniacal, atendidas no período de janeiro a junho de } 1988 . \\
\text { Procedimento: após separar a clara da gema, a clara foi batida até formar espuma consistente. Feito } \\
\text { limpeza da área lesada, com água morna, em seguida secada bem e aplicada clara com auxílio de } \\
\text { algodão. A área foi mantida descoberta por } 20 \text { a } 30 \text { minutos para secar, e depois colocado fralda. } \\
\text { Após o primeiro uso, a clara batida foi guardada em frasco tampado e utilizado durante o dia, } \\
\text { respeitando o espaço de } 7 \text { horas de uso. O procedimento foi repetido até o desaparecimento dos } \\
\text { sinais de dermatite Na escolha do ovo, deu-se preferência aqueles com a aparência opaca e áspera } \\
\text { da casca e que não apresentavam mobilidade quando o mesmo era movimentado. }\end{array}$ & $\begin{array}{l}\text { A duração média dos episódios foi de } 3 \text { dias. Em } \\
51,4 \% \text { dos casos (18) apresentaram duração mínima } \\
\text { de episódio, } 2 \text { dias após a aplicação da clara de ovo, } \\
\text { enquanto } 2,9 \% \text { ( } 1 \text { caso) teve duração superior a } 6 \\
\text { dias e não houve cooperação da mãe. A maior } \\
\text { incidência de assaduras ocorreu em crianças de } 7 \text { a } \\
11 \text { meses (19casos), e menor em crianças de } 13 \text { a } \\
18 \text { meses (fase de educação dos esfíncteres) onde } \\
\text { a criança fica maior tempo de fralda. Todos os casos } \\
\text { de dermatite amoniacal tratados regrediram } \\
\text { totalmente. }\end{array}$ \\
\hline $\begin{array}{l}\text { Rogenskl, } \\
\text { Guedes, } \\
\text { Baptista, } \\
\text { Costa(19) }\end{array}$ & $\begin{array}{l}\text { Amostra: } 4 \text { pacientes com idades entre } 22 \text { e } 69 \text { anos, com infecção visceral. Procedimento: realizada } \\
\text { cultura em todos os casos sendo detectados Pseudomonas aeruginosa no } 1^{\circ} \text { caso, Staphylococcus } \\
\text { aureus e Citrobacter sp no } 2^{\circ} \text { caso, Enterococcus fecalis e leveduras no } 3^{\circ} \text { caso, e Staphylococcus sp, } \\
\text { Escherichia coli e Enterococcus fecalis no } 4^{\circ} \text { caso. Todos foram submetidos a antibioticoterapia } \\
\text { específica, após antibiograma. Houve consentimento da equipe médica responsável e esclarecimento } \\
\text { aos pacientes quanto ao novo método de tratamento. Foram elaborados rotina espećfica e } \\
\text { treinamento da equipe de enfermagem. Realizada irrigação da ferida com solução de papaína } 4 \% \text {, } \\
\text { utilizando auxílio de sonda de Nelaton; em seguida drenagem postural por aproximadamente } 5 \\
\text { minutos; posteriormente, curativo oclusivo. Em apenas uma das lesões foi utilizado solução de } \\
\text { papaína a } 2 \% \text { nas primeiras } 24 \text { horas e após, mudou-se a concentração para } 1 \% \text {, por se tratar de } \\
\text { irrigação contínua de peritônio. Após } 48 \text { horas, a irrigação foi suspensa, e mantido curativo com } \\
\text { papaína } 4 \% \text {. Os curativos foram realizados a cada } 8 \text { horas. }\end{array}$ & $\begin{array}{l}\text { Em todos os casos, houve redução acentuada da } \\
\text { secreção após } 72 \text { horas, e início de formação do } \\
\text { tecido de granulação. O tempo médio de } \\
\text { cicatrização total foi de } 30 \text { dias. Verificou-se } \\
\text { excelente resposta dos pacientes ao tratamento } \\
\text { aplicado, principalmente na irrigação contínua com } \\
\text { solução de papaína a } 1 \% \text {. }\end{array}$ \\
\hline
\end{tabular}

Quadro 2. Segunda parte da sinopse dos artigos analisados. REBEn 1988-1995.

\section{CONSIDERAÇÕES FINAIS}

Nos estudos de revisão sistemática da literatura não cabem conclusões, uma vez que o quadro sinóptico produzido na pesquisa deve ser analisado pelo leitor, o qual elabora as próprias conclusões. Acreditamos ser oportuno, porém, destacar que do ponto de vista da produção de evidências consistentes, a maioria dos estudos publicados encontra-se incipiente, pela fragilidade no delineamento das pesquisas. 


\begin{tabular}{|c|c|c|}
\hline Identificação & Amostra, Procedimento e Método de Análise & Resultados \\
\hline Tiago(20) & $\begin{array}{l}\text { Amostra: } 47 \text { pacientes de ambos os sexos, com idades entre } 30 \text { e } 80 \text { anos, apresentando úlcera de } \\
\text { estase venosa infectadas. Procedimento: limpeza da lesão com SF e anti-sepsia com PVPI 1\%; } \\
\text { cobertura da lesão com curativo de Carvão Ativado; fixação nas bordas com fita hipoalérgica; curativo } \\
\text { secundário com gaze de algodão e bota de unna. Para aplicação da bota de unna, o paciente foi } \\
\text { colocado em repouso (decúbito horizontal) por } 30 \text { minutos, com membros inferiores elevados a } 45 \\
\text { graus. A troca do curativo foi feita a cada } 3 \text { a } 7 \text { dias. Foram feitos em } 12 \text { casos, de } 1 \text { a } 5 \text { curativos; em } \\
19 \text { casos, de } 6 \text { a } 10 \text { curativos. Estudo realizado durante } 12 \text { meses. }\end{array}$ & $\begin{array}{l}4,3 \% \text { dos pacientes abandonaram o tratamento; } \\
8,5 \% \text { não tiveram as úlceras cicatrizadas; } 87,2 \% \\
\text { tiveram suas feridas cicatrizadas. O menor tempo de } \\
\text { cicatrização foi de } 14 \text { dias, e o maior tempo foi de } \\
300 \text { dias. Ao longo do tratamento, houve diminuição } \\
\text { da quantidade de secreção, melhora da dor, } \\
\text { diminuição do consumo de analgésicos, redução do } \\
\text { edema, ausência de alergia ao produto. O tempo de } \\
\text { tratamento variou de } 2 \text { a } 16 \text { semanas, sendo que no } \\
\text { tratamento convencional o tempo era de } 10 \text { a } 40 \\
\text { semanas. }\end{array}$ \\
\hline Marinho(21) & $\begin{array}{l}\text { Amostra: Prontuário de } 19 \text { pacientes, sendo } 12 \text { mulheres e } 7 \text { homens, com idades entre } 33 \text { e } 73 \text { anos; } \\
\text { portadores de úlcera de pressão. Procedimento: busca ativa nos prontuários dos pacientes. Análise } \\
\text { das informações dos profissionais de enfermagem responsáveis pela troca dos curativos. }\end{array}$ & 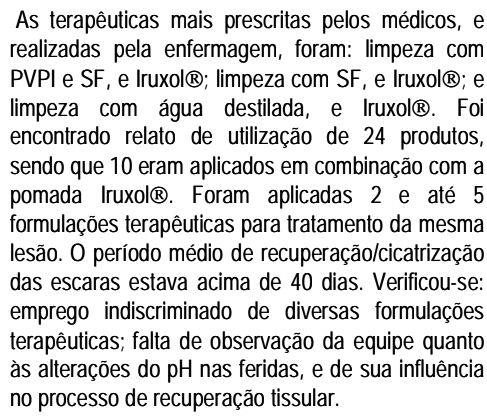 \\
\hline $\begin{array}{l}\text { Borges, } \\
\text { Gomes, } \\
\text { Saar(22) }\end{array}$ & $\begin{array}{l}\text { Amostra: uma (1) ferida crônica, decorrente de insuficiência venosa em MID, com } 99 \mathrm{~cm}^{2} \text { de área e } 0,3 \\
\mathrm{~cm} \text { de profundidade, tecido necrótico de cor marrom, consistência amolecida e drenagem de exsudato } \\
\text { seroso. Procedimento: realizada limpeza da mesma ferida tanto com produtos em quantidade e } \\
\text { técnica tradicional (SF, luvas de procedimento, pacote de gazes, PVPI tópico e degermante, } \\
\text { Cortoplast, pacote de curativo) como no padronizado (SF, luvas de procedimento, pacote de gazes, } \\
\text { sabão neutro, agulha } 25 X 8 \mathrm{~mm} \text { ). Para calcular o custo do curativo, tomou-se por base a mesma ferida } \\
\text { e os materiais necessários para o tratamento em um período de uma semana, comparando o } \\
\text { tradicional (uso de colagenase, ou neomicina) com outros produtos (Sacarose, Sulfadiazina de Prata, } \\
\text { Ácidos Graxos Essenciais, Fibras de Viscose e Poliéster, Hidrocolóide, Alginato de Cálcio). Foram } \\
\text { utilizados valores referentes a fevereiro de } 1999 \text {. }\end{array}$ & $\begin{array}{l}\text { O diferencial no custo foi observado na limpeza, que } \\
\text { eleva devido ao número de trocas. O custo da } \\
\text { limpeza atualizada é } 5,4 \% \text { menor do que no } \\
\text { tradicional. O custo final dos curativos preconizados, } \\
\text { que utilizam as novas coberturas e que exige menor } \\
\text { número de trocas, apresentou custo inferior ao dos } \\
\text { curativos tradicionais. }\end{array}$ \\
\hline
\end{tabular}

Quadro 3. Terceira parte da sinopse dos artigos analisados. REBEn 1996-2003.

Como reflexões finais, acreditamos que a temática "tratamento de feridas" constitui um campo enorme de investigação, o qual tem sido pouco explorado pelos enfermeiros. Esse fenômeno assume relevância na medida em que é a enfermagem que geralmente se ocupa da realização dos curativos.

\section{REFERÊNCIAS}

1. Declair V. Tratamento de úlceras crônicas de difícil cicatrização com ácido linoleico. Jl Bras Med 2002 jun;82(6):3-7.

2. Grupo de Estudos de Feridas do Hospital das Clínicas da Universidade de Campinas. Manual de tratamento de feridas. $2^{\mathrm{a}}$ ed. Campinas (SP): Hospital das Clínicas/UNICAMP; 2000.

3. Meneghin P, Soares L. Avanços em curativos. In: Fernandes AT, Fernandes MOV, Ribeiro Filho N. Infecção hospitalar e suas interfaces na àrea de saúde. São Paulo (SP): Atheneu; 2000. p. 998-1007.

4. Dantas SRPE. Aspectos históricos do tratamento de feridas. In:Jorge AS, Dantas SRPE. Abordagem multiprofissional do tratamento de feridas. São Paulo (SP): Atheneu; 2003. p.3-6.

5. Hess CT. Tratamento de feridas e úlceras. Rio de Janeiro (RJ): Reichmann \& Affonso Ed; 2002.

6. Dantas Filho VP. Aspectos éticos do tratamento de feridas. In: Jorge AS, Dantas SRPE. Abordagem multiprofissional do tratamento de feridas. São Paulo (SP): Atheneu; 2003. p. 7-10.

7. Bajay JM, Jorge AS, Dantas SRPE. Técnicas básicas para a realização de curativos no âmbito hospitalar. In: Jorge AS, Dantas SRPE. Abordagem multiprofissional do tratamento de feridas. São Paulo (SP): Atheneu; 2003. p. 69-79.

8. Ailinger RL. Contributions of qualitative research to evidence-based practice in nursing. Rev Lat-am Enfermagem 2003 maio-jun; 11(3):275-9.

9. Wannmacher L, Fuchs FD. Conduta terapêutica embasada em evidências. Rev Assoc Med Bras 2000 jul/set;46(3):237-41.

10. Muñoz WIS, Takayanagui AMM, Santos CB, Sanches-Weatman O.
Revisão sistemática da literatura e metanálise: noções básicas sobre seu desenho, interpretação e aplicação na área de saúde. In: Anais do $8^{\circ}$ Simpósio Brasileiro de Comunicação em Enfermagem; 2002 mai 2-3; Ribeirão Preto (SP), Brasil. [citado em 25 jul 2004]. Disponível em: URL: http://www.proceedings.scielo.br/pdf/sibracen/ n8v2/v2a074.pdf

11. Polit DF, Beck CT, Hungler BP. Compreensão do delineamento da pesquisa quantitativa. In: Polit DF, Beck CT, Hungler BP. Fundamentos de pesquisa em enfermagem. Métodos, avaliação e utilização. Porto alegre (RS): ARTMED; 2004. p. 163-98.

12. Azevedo DO. Tratamento de queimados com a membrana amniótica. Rev Bras Enferm 1978 abr-jun; 31(2):243-51.

13. Haddad MCL, Vannuchi MTO, Chenso MZB, Hauly MCO. O uso do açúcar nas feridas infectadas. Rev Bras Enferm 1983 abr-jun; 36(2):152-4.

14. Robazzi MLCC, Bechelli MHM, Levy CE, Moriya TM. Cateteres intravenosos - estudo de condições bacteriológicas e avaliação da assistência de enfermagem. Rev Bras Enferm 1984 jan-mar; 37(1):18-25.

15. Monetta L. Uso da papaína nos curativos feitos pela enfermagem. Rev Bras Enferm 1987 jan-mar; 40(1):66-73.

16. Bernardo CLE, Souza IAF, Colavitti C, Garcia C. Própolis cicatrizante e antibiótico natural. Rev Bras Enferm 1990 jan-dez; 43(1/ 4):101-6.

17. Silva MJ, Menezes ELM, Souza YL, Gimenez NC. Avaliação do filme transparente de poliuretano em queimaduras e áreas doadoras de pele. Rev Bras Enferm 1990 jan-dez; 43(1/4):117-22. 
18. Silva LJ, Confalonieri AMMM, Amorin FS. Relato de uma experiência utilizando-se a clara de ovo na dermatite amoniacal no centro de convivência do Instituto "Dante Pazzanese" de Cardiologia. Rev Bras Enferm 1991 abr-set; 44(2/3):136-40.

19. Rogenski NMB, Guedes ML, Baptista CMC, Costa LDF. Uso da papaína em infecções de vísceras. Rev Bras Enferm 1995 abr-jun; 48(2):140-3.
20. Tiago F. Tratamento de úlceras de estase venosa com bota de unna e carvão ativado. Rev Bras Enferm 1996 abr-jun; 49(2):215-24.

21. Marinho AM. Atenção nos cuidados de enfermagem das escaras quanto às associações terapêuticas. Rev Bras Enferm 1997; 50(2):257-74 .

22. Borges EL, Gomes FSL, Saar SRC. Custo comparativo do tratamento de feridas. Rev Bras Enferm 1999 abr-jun; 52(2):215-22. 